\title{
BMJ Open Quality Hepatitis Service Provision at HMP Birmingham: Progressing a Previous Service Improvement Plan
}

\author{
Tooba Arif ${ }^{1,2}$
}

To cite: Arif T. Hepatitis Service Provision at HMP Birmingham: Progressing a Previous Service Improvement Plan. BMJ Open Quality 2018;7:e000192. doi:10.1136/ bmjoq-2017-000192

- Additional material is published online only. To view please visit the journal online (http://dx.doi.org/10.1136/ bmjoq-2017-000192)

PatientSafety Prize Session, Royal Society of Medicine, London, UK, November 2017National Foundation Doctors Presentation Day,Bristol, UK, January 2016

Received 28 August 2017 Revised 6 November 2018 Accepted 10 November 2018

Check for updates

(C) Author(s) (or their employer(s)) 2018. Re-use permitted under CC BY-NC. No commercial re-use. See rights and permissions. Published by BMJ.

${ }^{1}$ West Midlands East Health Protection Unit, Public Health England, Birmingham, West Midlands, UK

${ }^{2}$ Division of Surgery and Interventional Science, University College London, London, UK

Correspondence to

Dr Tooba Arif;

tooba.arif@nhs.net

\begin{abstract}
Introduction Hepatitis $B$ is a vaccine-preventable disease, and hepatitis $C$ is amenable to treatment. Both are highly prevalent in the prison population. This project provides a comprehensive evaluation of current hepatitis services at Her Majesty's Prison Birmingham, assessing progress since previous work and proposing further suggestions for improvement.
\end{abstract}

Methods A review of hepatitis services was undertaken in 2013, in the context of underperformance against national targets. This revealed that the hepatitis $\mathrm{B}$ vaccination and hepatitis $\mathrm{C}$ testing coverage was $22 \%$ and $0 \%$, respectively. A resulting service improvement plan included interventions such as the development of a bloodborne virus (BBV) policy, implementing opt-out testing and introducing dried blood spot testing for ease of administration. In 2015, national guidelines were used to evaluate current practice, with comparison to previous practice. The indicators assessed included BBV policy, vaccination and testing protocols, prisoner education and reporting of results. Discussions were held with prison stakeholders to address areas that required development, producing a revised action plan.

Results Hepatitis services were available to all prisoners starting their sentence in 2015, $n=4998$. Testing was offered on an opt-out basis to all entrants, increasing the testing coverage by $7.6 \%$ from 2013 . Vaccination was offered to $57 \%$ of entrants, with coverage slightly lower than 2013, largely due to prisoner refusal. In light of this, many strategies were devised to educate prisoners, increase opportunities to receive testing and vaccination, and decrease the risk of patients being lost to follow-up. An update in 2016 saw progress in many of these areas. Discussion Being in prison provides offenders with stability in their lifestyle and easier access to healthcare services. By optimising these services in line with national guidance, and implementing specific strategies to encourage uptake of hepatitis testing and vaccination, we may be better able to serve this vulnerable sector of the population.

\section{BACKGROUND}

\section{Problem description}

The process of quality improvement aims to enhance patient care by implementing systematic, positive changes to existing service provision. This project combines both qualitative and quantitative approaches to provide a comprehensive, objective evaluation of current hepatitis services at Her Majesty's Prison (HMP) Birmingham, assess progress since previous work and propose further suggestions. 'Hepatitis' and 'bloodborne viruses (BBV)' will refer to both hepatitis B and C unless specified. The project encompasses the public health domains of health protection, health improvement and service improvement.

HMP Birmingham is a category B prison situated near central Birmingham and was managed at the time of this study by G4S. ${ }^{1}$ Its prisoner body comprises 150 adult males; including those who are on remand, undergoing trial or who have already been sentenced. ${ }^{1}$ The Trust in charge of delivering health services at the prison is Birmingham \& Solihull Mental Health Foundation Trust. ${ }^{2}$ Access to sexual health and hepatitis services features within this remit. ${ }^{1}$

As of 15 May 2015, 84372 people in England and Wales were in imprisonment, $95 \%$ of whom were male. ${ }^{3}$ This constituted an over $90 \%$ rise in the prison population since 1993, and it is projected to continue to grow. $^{3}$ In contrast, the overall number of staff employed within the prison service has fallen by $29 \%$ since $2011,{ }^{3}$ a trend which suggests that implications may arise for providing a consistent level of healthcare for prisoners. Another impediment for prisoner health is conveyed by the fact that, as of March 2015, 70 of the 117 prisons in England and Wales were overcrowded, ${ }^{3}$ presenting a challenge for staff and service distribution.

The demographics of the prison population contrast with those of the general population in a number of ways that require unique attention when determining health service provision. Minority ethnic groups form $26 \%$ (21 880) of the prison population in contrast to $10 \%$ of the general population. ${ }^{3}$ Twelve per cent of prisoners are foreign nationals ${ }^{3}$ which implies diversity in the morbidity that could be found. Fourteen per cent of the prison population have been incarcerated directly in relation to illicit drug offences ${ }^{3}$; moreover, associated behaviour is prominent among those imprisoned for other offences, 
with $64 \%$ of prisoners overall reporting drug use in the 4 weeks before being placed in custody. ${ }^{3}$

The most recent comprehensive survey regarding hepatitis rates in prisoners was performed in the year 19971998 which indicated that hepatitis C virus (HCV) affected $9 \%$ of male and $11 \%$ of female prisoners, ${ }^{4}$ compared with $0.4 \%$ of the general population. ${ }^{5}$ Many BBV risk factors are specifically applicable to the prison setting. Estimates vary considerably due to presumed under-reporting, but it is suggested that around $6 \%$ of adult male prisoners inject while in prison, with $75 \%$ of these sharing needles or syringes. ${ }^{6}$ Sharing of personal hygiene equipment including toothbrushes, illicit tattooing and physical altercations resulting in bleeding are further risk factors. Additionally, sexual activity—both consensual and coercive-can pose a BBV risk. One survey found that $3 \%$ of adult male prisoners have had penetrative sex with another male while in prison. ${ }^{6}$

There is a paucity of literature pertaining to hepatitis services in the prison population. This is highlighted by the fact that only six studies, of which only two were randomised controlled trials, were identified in a recent systematic review $^{7}$ evaluating the efficacy of measures to increase prisoner HCV testing and subsequent treatment uptake. Limitations included restricting the search to online databases, and the filtering of papers by language and to the last decade. As studies where an intervention was trialled without mention of a comparator were excluded, some interesting data may also have been missed. Risk of bias was assessed by a validated tool and although no papers were excluded for this reason, no study was wholly at below moderate risk of bias. The authors found that routine HCV testing of prisoners is not universal or consistent even in the developed world, where all the studies were based, despite this being a WHO recommendation. Studies focused on testing but there was less emphasis on subsequent follow-up to ensure treatment was administered. Interventions to enhance testing uptake included on-site screening with prisoner education, the introduction of dried blood spot testing (DBST) and a combination riskbased and birth-cohort screening approach; all of which increased testing rates to various degrees. On-site screening increased this twofold, whereas implementing DBST only improved it when provided in combination with other services. Birth-cohort-based screening decreased testing specificity when added to risk-based screening and also did not significantly improve testing sensitivity, indicating that it is of limited advantage, although this was based only on the results of one study. Recommendations as a result of the review were for more robust research into which particular interventions are effective and also for treatment to be commenced and preferably completed while the patient is still detained.

Another systematic review ${ }^{8}$ placed fewer restrictions on search results, including language and non-peer-reviewed literature, and therefore retrieved a larger number of results which focused on testing for communicable diseases in European prisons. Unsurprisingly, the majority was recognised as only low-moderate level evidence, and there was much heterogeneity among studies. Results indicated a higher prevalence of diseases including hepatitis in the prison population, justifying a public health focus in this area. Early testing was associated, although not significantly, with higher testing uptake. Risk-based testing was considered a valid option for HCV, and the use of less invasive methods such as DBST increased prisoner cooperation in two studies. These methods were also cited as logistically easier.

Being in prison may provide offenders with stability in their lifestyle and the opportunity to access services that they may not have encountered or engaged with while in the community. Therefore, if comprehensive healthcare services are available and adequately resourced, this could potentially provide a platform for an increased likelihood of new diagnoses.

\section{Available knowledge Quantitative}

A previous report by Public Health England (PHE) identified that in 2013, out of a total of 6452 receptions to HMP Birmingham, the number of hepatitis $\mathrm{C}$ tests performed within 31 days was 0 , therefore there was $0 \%$ testing coverage recorded. ${ }^{9}$ This may be influenced by lack of recording locally, or lack of reporting to PHE, but as it stood this figure was disappointing. The recommendation for opt-out testing took place in late 2013, for implementation in prisons in 2014, and may subsequently influence these statistics.

A second report found that the hepatitis B virus (HBV) vaccination coverage at HMP Birmingham in 2013 overall was $22 \% .^{10}$

\section{Qualitative}

A qualitative review of hepatitis services at all of the prisons in the West Midlands, including HMP Birmingham, was also undertaken in October-November 2013 by PHE. ${ }^{11}$ The context of this work was underperformance of the area's prisons against other regions, with hepatitis $B$ vaccination and hepatitis $\mathrm{C}$ testing rates in the West Midlands being the lowest in England. A self-assessment questionnaire was sent to the provider institution's healthcare staff, with the aim of ascertaining current practice in BBV service commissioning and delivery, including prevention, governance, immunisation, testing and referrals for treatment.

\section{Intended improvement}

In view of this work in 2013, initial interventions were suggested to improve BBV services, after reviewing which areas required improvement and comparing performance with data from other institutions that were studied. The outcome of this was an individualised service improvement plan (SIP) to keep track of progress (see the Implementation of previous recommendations section).

\section{Current guidelines}

The relevant themes within the four sets of guidelines and standards used in this project are outlined below. 
STANDARD $1^{12}$

Prison Health Performance and Quality Indicators, 2008.

1. HBV vaccine coverage of $\geq 80 \%$.

2. BBV policy.

3. Patient information.

4. Access to barrier protection and lubricants.

\section{STANDARD $2^{13}$}

National Institute for Health and Care Excellence Guideline PH43, 2012.

1. Pretest and post-test discussions.

2. Patient information.

3. Staff training.

4. BBV testing.

5. Lab reporting.

\section{STANDARD $3^{14}$}

'Green Book' hepatitis B vaccination schedule, 2006.

1. Immunisation against $\mathrm{HBV}$ for all new and existing prisoners.

2. Immunisation and testing to be performed simultaneously.

3. Use of 'very rapid schedule'.

4. Five-year booster vaccination.

\section{STANDARD $4^{15-17}$}

Opt-out BBV testing algorithms: National Partnership Agreement between PHE, National Health Service (NHS) England and National Offender Management Service, 2013.

1. Vaccination algorithm.

2. Opt-out testing algorithm.

\section{Specific aims}

- The principal aim of this project was to ascertain the extent to which national standards and guidelines for prison hepatitis services were adhered to in HMP Birmingham in 2015.

Further aims included:

- Identification of whether all actions or recommendations from the previous SIP (see the Implementation of previous recommendations section) were implemented or not, with reasons.

- Commenting on the nature of quality improvement observed over the 2-year period, including how recorded statistics were affected.

- Identifying reasons for difficulties in meeting national guidance from the current review.

- Proposing methods to address these obstacles.

\section{Assessment of problem}

'Quality' care can be defined as the standard of care set by the national guidance. Current quality of services is measured against this:

- Quantitatively in a dichotomous nature referring to adherence, and also by expressing statistics for testing and vaccination coverage.
- With qualitative evidence to elaborate on areas of good practice but also explain reasons for why gaps exist in current service provision.

\section{Sample}

Hepatitis services were open to all prisoners who started their sentence in 2015, $\mathrm{n}=4998$.

\section{Data collection}

Quantitative

- The statistical data relating to hepatitis B vaccination over the year 2015 was gathered using specific read codes that had been input by prison nurses on the prison patient record system-SystemOne.

- A spreadsheet was kept and regularly updated by BBV nurses at HMP Birmingham, detailing hepatitis $\mathrm{C}$ testing for each calendar month of the year 2015. As all prisoners who were tested were entered on this, one can determine the percentage from the total receptions to the prison in 2015.

- These can be used to assess progress in statistics from those collected by PHE in 2013.

\section{Qualitative}

- A number of discussions based around a questionnaire tool (online supplementary appendix 1), which was modified to take into account the baseline from previous work, were held with healthcare staff at HMP Birmingham. This differed from previously, where a similar but generic tool had been completed and returned by the institution.

\section{QUALITY IMPROVEMENT TOOLS}

The primary quality improvement tool used in this project was clinical audit against the standards that are described in the Current guidelines section. Additionally, performance benchmarking is routinely used by PHE to drive institutions towards meeting the expected targets which was how the project initially came about in light of HMP Birmingham's underperformance against national standards. Local targets were again dictated by the clinical guidelines mentioned. During the discussion with the key stakeholders, process mapping was employed to identify opportunities in the prisoner journey where interventions could improve their care and the prison healthcare system's compliance with targets. For example, when mapping the prisoner journey from entry to release or transfer, multiple time points were identified where BBV awareness could be raised, with the hope that this would subsequently encourage uptake of testing or vaccination. Providing education at reception screening appointments, weekly prisoner forum meetings and on dedicated health promotion days was discussed (see the Strategies for improvement section).

\section{Limitations}

Some of the limitations identified in the previous review were addressed and overcome by the design of this project, for example the use of inperson discussion based around 
the questionnaire as opposed to relying on the institution filling out the questionnaire unassisted. Talking through questions and allowing staff to answer most questions in an open fashion also reduced possible researcher bias.

As this was a re-review, it was somewhat limited in scope by the first review's content and the subsequent SIP derived from this.

It is recognised that the results are relying on self-collected statistics, but this sees an improvement from previously where no statistics were collected at all and figures stood at $0 \%$ for hepatitis $\mathrm{C}$ testing coverage. There is however potential for user error which could affect the accuracy of the data.

The SIP resulting from the 2013 work may have been better tested by the employment of plan, do, study, act cycles pertaining to individual elements of the SIP. This, or a 'model for improvement' approach where measurable outcomes are tested initially on a small scale and then refined, is recommended to test the new action plan resulting from this review (online supplementary appendix 2) in the future.

\section{Ethics}

The spreadsheets recorded by nursing staff were shared via secure email, stored on an encrypted memory stick and destroyed as soon as results had been collected. Names of individual prisoners were not mentioned during the questionnaire-based discussions.

Prison healthcare staff gave written consent for this paper to be published.

\section{RESULTS}

\section{Current adherence to guidance}

The items in bold in table 1 below are those that have improved since the previous review. All points from the guidance are combined.

\section{Implementation of previous recommendations}

Table 2 highlights the implementation status of the recommendations from the previous review.

\section{Quantitative data}

Table 3A-C convey current hepatitis vaccination and testing figures at the prison, with table $3 \mathrm{C}$ also describing the overall change since the previous review.

\section{Strategies for improvement}

Some improvement has been seen in guideline compliance and testing coverage, with a slight decrease in vaccination uptake. Prisoners who refused or were not offered intervention largely contributed to performance statistics. Strategies agreed on to improve this include through education and communication, better organisation and improving the range of available testing methods as discussed below.

\section{BBV policy}

The drawing up of a formal, written policy is in progress. In the interim period, the staff felt they would benefit from advice and assistance regarding aspects of BBV management that will eventually form part of this. Specifically, there is no set pretest or post-test checklist at present for discussion with prisoners who undergo BBV testing. The implementation of these would serve to standardise the information provided at sensitive times, to ensure it is conveyed in a suitable style for a lay audience, and to ensure that all key information is covered.

\section{Information provision}

It may be beneficial and efficient to use the same information as provided in the proposed pretest and post-test checklists to educate prisoners. The prison staff use the motto 'every contact counts' to promote BBV awareness, whereby prisoners are given verbal information on induction and prior to intervention, but also at every healthcare appointment.

There are posters available to raise awareness passively using illustrations, and are available in card format for distribution to prisoners. Other potential opportunities for increasing BBV awareness were highlighted during the discussions, including incorporating this into weekly forum meetings for inmates, health promotion days and NHS England's email bulletin to prisoners. The prison drug services team are an ideal group of people to assist in promoting and implementing BBV services due to the close relation of these diseases to this demographic group. Another possibly effective idea could be to employ the use of an 'expert patient', ideally a former prisoner, who could perhaps identify better with the target audience and encourage those refusing intervention.

Language line, a telephone translation service, is in use covering the common foreign languages spoken by prisoners. This is used instead of inperson interpreters due to the vast range of languages spoken. Braille was not deemed a necessary permanent resource due to the rarity of a prisoner requiring it, but it was recognised that large print may be beneficial in view of the extensive age range of prisoners. Translated reading material could be a simple intervention, alongside which the staff feel they would benefit from hepatitis-related literature. Furthermore, from a wider public health perspective, the prison staff could benefit from a list of legally notifiable diseases as they were currently unaware of this and acute infectious hepatitis features on this list. ${ }^{18}$

\section{Hepatitis B immunisation}

An HBV vaccination coverage of $19 \%$ constitutes a $3 \%$ drop from 2013 and does not meet Standard 1 where this is required to be $\geq 80 \%$. A large contributor to this low vaccination coverage figure is prisoners who refused. In the instance that all those who refused, for reasons other than they were already immune, had actually accepted and been vaccinated $(n=1320)$, coverage would have jumped to $48 \%$. Had all eligible prisoners been offered vaccination in the first place, this number can be anticipated to be even higher. The key message from this is that measures have to be implemented to ensure all prisoners are offered vaccination on 


\begin{tabular}{|c|c|c|}
\hline Item & Partly & Notes \\
\hline Written policy. & & $\begin{array}{l}\text { Standard operating procedures introduced- } \\
\text { formal written policy in progress. }\end{array}$ \\
\hline Prisoner education. & & $\begin{array}{l}\text { Available, although further ways to improve this } \\
\text { were identified. }\end{array}$ \\
\hline \multicolumn{3}{|l|}{$\geq 80 \%$ Vaccination coverage. } \\
\hline Condom and lubricant access. & & $\begin{array}{l}\text { Now freely available on request, without } \\
\text { prescription. }\end{array}$ \\
\hline \multicolumn{3}{|l|}{$\begin{array}{l}\text { Standardised pretest and post-test } \\
\text { discussions. }\end{array}$} \\
\hline $\begin{array}{l}\text { Adequate information provided, addressing } \\
\text { various needs, awareness sessions. }\end{array}$ & & $\begin{array}{l}\text { Translated information still lacking, and } \\
\text { 'expert patients' from among peers are not } \\
\text { currently available. }\end{array}$ \\
\hline Ongoing education and training for prison staff. & & $\begin{array}{l}\text { Wider nursing team still need DBST training to } \\
\text { assist with BBV services. }\end{array}$ \\
\hline $\begin{array}{l}\text { Testing: designated staff, offer inreach } \\
\text { services, procedure to provide results, } \\
\text { access to DBST, handover arrangements for } \\
\text { transfer, medical hold. }\end{array}$ & & $\begin{array}{l}\text { Inreach services still in progress. No medical } \\
\text { hold available. }\end{array}$ \\
\hline \multicolumn{3}{|l|}{$\begin{array}{l}\text { Laboratory to ensure PHE notified of new } \\
\text { cases. }\end{array}$} \\
\hline $\begin{array}{l}\text { Immunisation offered to all new and existing } \\
\text { prisoners. }\end{array}$ & & $57 \%, 2015$. \\
\hline \multicolumn{3}{|l|}{ Testing done simultaneously with vaccination. } \\
\hline \multicolumn{3}{|l|}{ Very rapid schedule used $(0,7,21$ days). } \\
\hline $\begin{array}{l}\text { Recommend 12-month and 5-year booster } \\
\text { doses. }\end{array}$ & & Sporadic recommendations are made. \\
\hline $\begin{array}{l}\text { Hepatitis B: All prisoners to be offered } \\
\text { vaccine, or continue course. Test to be } \\
\text { performed simultaneously. If negative, } \\
\text { provide reassurance and harm minimisation, } \\
\text { and complete course. If positive, suspend } \\
\text { vaccination and refer for further testing. }\end{array}$ & & Offer was not made to all prisoners. \\
\hline $\begin{array}{l}\text { Hepatitis C: Testing offered to all current } \\
\text { and new prisoners (within } 72 \text { hours). Those } \\
\text { with negative or false-positive results } \\
\text { receive a repeat risk assessment and test } \\
\text { offer after every risk event or annually. } \\
\text { Those testing positive receive confirmatory } \\
\text { testing and referral to secondary care. }\end{array}$ & & $\begin{array}{l}100 \% \text { were offered, however not all who tested } \\
\text { positive were commenced on the management } \\
\text { pathway. }\end{array}$ \\
\hline
\end{tabular}

Bold text indicates those that have improved since the previous review.

In terms of current adherence to guidelines, 'green' corresponds with adherence, 'orange' with partial adherence, and 'red' with nonadherence.

BBV, bloodborne virus; DBST, dried blood spot testing; PHE, Public Health England.

reception, and that sufficient education and encouragement is provided to reduce refusal.

Immunisation against hepatitis B is offered to new prisoners on their second day during a 'Wellman clinic'. Therefore, attendance at this clinic determines whether the offer is made early or not. Otherwise, they may hear about it at another appointment, through their peers or one of the information sources available as above.

There is currently no way to identify a list of prisoners who have not been vaccinated without physically searching through all healthcare records on SystemOne. This could perhaps be addressed by either regularly extrapolating data from SystemOne into a list detailing each prisoner's immunisation status, or building this manually in the form of a spreadsheet similar to what is used for BBV testing. In addition to this, prisoners who have refused immunisation and may require extra information and encouragement could be more easily identified in this way. They are verbally encouraged at the point of refusal but there is no clear system for following 
Table 2 Implementation of previous recommendations

No Action Status Notes

Actions for NHS England

\begin{tabular}{l|l|l|l|l|l}
\hline 1 & Develop BBV policy to include: education, & & & This is in progress. A generic
\end{tabular} hepatitis $B$ vaccination, BBV testing, pretest $\quad$ example policy will be sent to and post-test checklist and/or discussion prompts, guidance on providing test results, treatment pathway, referral guidelines, clinical management protocol.

\begin{tabular}{l|l}
\hline 2 & Assist with DBST implementation.
\end{tabular}
HMP Birmingham to adapt and personalise for themselves.

Actions for HMP Birmingham

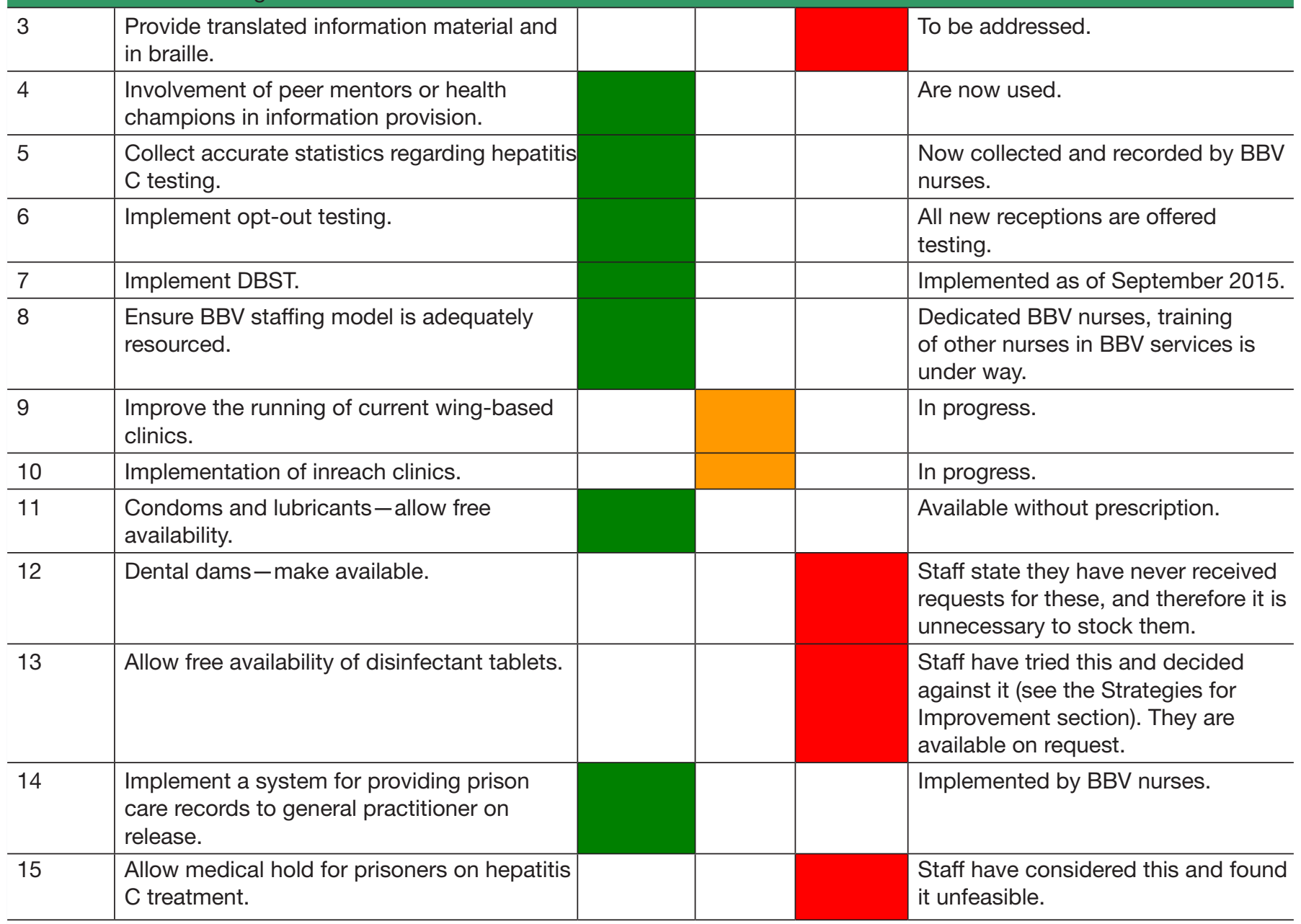

Status key: green, completed; amber, in progress; red, yet to be addressed.

BBV, bloodborne virus; DBST, dried blood spot testing; HMP, Her Majesty's Prison; NHS, National Health Service.

them up at present, with ad hoc offering of vaccination at future health-related appointments.

To address the high turnover of prisoners-on average 600 per month—with relatively short stays, the very rapid schedule of $0 / 7 / 21$ days is used.

Reducing non-attendance at appointments and increasing uptake of vaccination could be managed by, in addition to health promotion as discussed, by operating dedicated wing-based clinics where the services go to the prisoners instead of vice versa. Two out of 11 wings currently have this facility but it has been difficult to implement further due to insufficient healthcare or guard staffing and lack of available space.

A simplistic but potentially effective measure which could serve as a reminder to prisoners and also a record for when they are transferred or released, would be to provide the prisoner with a vaccination card with spaces for nurses to fill in dates when vaccine doses were received. Reminders for 12-month and 5-year booster doses could also be printed on this.

A worthwhile idea would be to use the opportunity presented by an appointment for testing to offer 


\begin{tabular}{|c|c|c|}
\hline Patients starting a sentence in 2015 & $\mathbf{N}$ & $\%$ \\
\hline Total receptions & 4998 & \\
\hline Total offered hepatitis B vaccination & 2590 & \multirow[t]{2}{*}{57} \\
\hline $\begin{array}{l}\text { Total already immune (and therefore } \\
\text { vaccination offer made but unnecessary) }\end{array}$ & 238 & \\
\hline $\begin{array}{l}\text { Total not offered vaccination for other } \\
\text { reasons }\end{array}$ & 2170 & 43 \\
\hline $\begin{array}{l}\text { Total declined offer of vaccination (out of } \\
\text { 2590) }\end{array}$ & 1456 & 56 \\
\hline $\begin{array}{l}\text { Total who declined due to existing } \\
\text { immunity }\end{array}$ & 136 & 5 \\
\hline Total who declined for other reasons & 1320 & 51 \\
\hline Total who did not decline (out of 2590) & 1134 & 44 \\
\hline Total who had at least first vaccination & 386 & 34 \\
\hline $\begin{array}{l}\text { Total who had at least first and second } \\
\text { doses }^{*}\end{array}$ & 290 & 26 \\
\hline $\begin{array}{l}\text { Total who had at least first, second and } \\
\text { third doses* }\end{array}$ & 190 & 17 \\
\hline $\begin{array}{l}\text { Total who had first, second, third and } \\
\text { booster dose* }\end{array}$ & 30 & 3 \\
\hline $\begin{array}{l}\text { Total who were due vaccination but did } \\
\text { not receive, for any reason }\end{array}$ & 238 & 21 \\
\hline Total patients with some immunity & 1270 & 25 \\
\hline
\end{tabular}

*Previous doses may have been provided elsewhere.

immunisation and vice versa, improving the uptake of both overall. To tie in with this, it may be effective to place a sentence at the bottom of test results letters to advise that vaccination against hepatitis $B$ is recommended, in the instance that the prisoner has not yet received this.

Direct notification of positive results to PHE by the prison BBV staff would provide a more accurate picture of how many new diagnoses are being made in the prison population on an annual basis. By receiving notifications in a timely manner, PHE would be able to assist prison staff in following up those who are diagnosed which contributes towards tackling the issue of prisoners being lost to follow-up either within or outside of the institution.

\section{Screening}

Reception screening is offered on the first day for every new entrant to the prison, using the opt-out testing algorithm. Spreadsheets are kept and regularly updated by

\begin{tabular}{lll}
\hline Table 3 (B) Hepatitis C testing data & \\
\hline Patients starting a sentence in $\mathbf{2 0 1 5}$ & $\mathbf{N}$ \\
\hline Total receptions & 4998 \\
\hline Total offered hepatitis C testing & $100 \%^{*}$ \\
\hline Total who were tested & 380 \\
\hline Testing coverage & $7.6 \%$ \\
\hline
\end{tabular}

${ }^{*}$ Testing is offered as part of a routine checklist on reception which every prisoner undergoes on induction to the prison. the lead BBV nurse detailing every new entrant who has been tested for hepatitis. Unfortunately, data regarding those prisoners who were already diagnosed, or those who refused testing, is not recorded on this spreadsheet. This could have been useful in ascertaining where improvements could be made to increase testing coverage, and may also have explained why quantitatively, testing coverage only saw modest improvement at $+7.6 \%$.

Those prisoners who are yet to be tested or who refused at reception receive the same verbal encouragement as those refusing $\mathrm{HBV}$ immunisation. HBV testing is not recorded on the spreadsheets which was picked up during discussion with prison staff. This is due to there not having been any observed cases in the recent past, but staff were reminded that it is still worthwhile doing so in case these do arise and also for statistical purposes.

The method of DBST has recently taken over from venous blood sampling which is quicker and caters to needle-averse patients. Oral fluid swabs are no longer in use due to the experience of a great number of inaccurate results with these. The aim is to train all prison nursing staff in performing DBST to ensure that every prisoner entering the institution is tested.

Results are provided within 1 week to prisoners or their general practitioners (GPs) in case of release. However, a problem arises if the individual is not registered with a GP in the community, discussed further below.

\section{Staffing}

Prison guard understaffing at HMP Birmingham has an adverse impact on the delivery of BBV services in a number of ways. The way to solve this in part has been identified as having inreach clinics where secondary care personnel attend the prison to relieve some of the logistical issues, but these are still in the process of implementation.

All prison staff have BBV awareness training as part of their induction. Additionally, training of healthcare staff is provided by Birmingham Community Trust annually. A gap in this has been identified as training of all prison nurses to use DBST kits which have recently been implemented. It would be useful to the prison staff to also include a hepatitis B and C overview as part of this training.

\section{Referrals}

The process of referral to secondary care, including for psychological and social support, for new cases is via the prison GP. Those who have tested negative receive a letter via the BBV nurse. Abnormal results are delivered in person by the GP, and the patient is booked into the blood screening clinic for a viral load and genotyping test. Anyone with a viral load $>12$ is prescribed Milton sterilisation tablets and referred to a hepatologist.

Medical hold is not routinely used for patients with hepatitis as priority is given to patients with cancer, and this is unlikely to change in the near future according to staff. 
Table 3 (C) Overall change

\begin{tabular}{l|l|l|l|l}
\hline \multicolumn{2}{l}{2013} & 2015 & \\
\hline Receptions & 6452 & 4998 & $+100 \%$ & $\begin{array}{l}\text { All prisoners are offered this as part of the standard } \\
\text { reception protocol. }\end{array}$ \\
\hline $\begin{array}{l}\text { Hepatitis C test offered } \\
\text { Hepatitis C testing } \\
\text { coverage: within 31 days }\end{array}$ & $0 \%$ & $7.6 \%$ & $+7.6 \%$ & $\begin{array}{l}\text { Data extrapolated from BBV spreadsheets, as } \\
\text { described in methodology. }\end{array}$ \\
\hline $\begin{array}{l}\text { Hepatitis B vaccination } \\
\text { offered }\end{array}$ & NR & $57 \%$ & $\begin{array}{l}\text { Cannot } \\
\text { comment }\end{array}$ & $\begin{array}{l}\text { Figure of 57\% includes those that vaccination was } \\
\text { discussed with and offered to, and those it was } \\
\text { discussed with but not subsequently offered to as the } \\
\text { patient was already immune. }\end{array}$ \\
\hline $\begin{array}{l}\text { Hepatitis B vaccination } \\
\text { coverage: at least one } \\
\text { vaccination }\end{array}$ & $22 \%$ & $19 \%$ & $-3 \%$ & $\begin{array}{l}\text { Vaccination coverage=number pof patients vaccinated } \\
\text { out of number in the eligible population (number of } \\
\text { new receptions in 2015 minus those ineligible as they } \\
\text { were already immune). The eligible population here is } \\
\text { n=4624. }\end{array}$ \\
\hline
\end{tabular}

BBV, bloodborne virus; NR, not recorded.

Care records are transferred to the community GP or new institution in case of release or transfer, and these are contacted directly in the case of new diagnoses. However, there is no system for prisoners who are not registered with a GP outside of the prison, and these are prone to being lost to follow-up. This is usually identified early as all new receptions are asked for GP details, and those who are not registered are noted and encouraged to do so while they are imprisoned.

\section{Interventions}

Disinfectant tablets for the sterilisation of personal equipment are funded as any other medication, and can now be requested without prescription at any healthcare-related appointment, a positive step towards balancing wastefulness while addressing necessity. Prison staff felt that it is not possible to have these tablets freely available to access as this has been tried before, and the tablets were being used in abundance, perhaps not even for their intended use. Tablets are supplied for 3 days on release, after which it is up to the prisoner to obtain more from their GP.

Before condoms are issued to a prisoner, they must be seen by a sexual health nurse in clinic. Here, education is provided in correct usage and disposal of condoms. Two are provided at any one time, and a repeat request form is available for both condoms and lubricants. This is enclosed in an opaque bag to ensure confidentiality. Dental dams are not currently available due to lack of demand.

Prisoners are informed of the availability of these interventions via health promotion at every healthcare contact, sexual health clinics and in BBV test results letters.

\section{Lessons and messages}

Hepatitis B is a vaccine-preventable disease, and hepatitis $\mathrm{C}$ is a very treatable one. Both are known to have a high prevalence in the prison population. By improving hepatitis services in the prison serving England's largest local authority area and city outside of London, ${ }^{19}$ new cases are more likely to be identified and treated, and those at high risk can be vaccinated to prevent onwards transmission.

From a commissioner's perspective, prophylaxis is cost-effective as opposed to treatment once the infection is acquired. Direct healthcare costs in this country of hepatitis $\mathrm{C}$ infection are currently over $£ 0.5$ billion per annum, and are increasing by $10 \%$ per year. ${ }^{4}$ Serious outcomes of having the disease, such as admission to hospital and death from end-stage liver disease and hepatocellular carcinoma are also rising. ${ }^{4}$ This highlights another reason why prevention, early diagnosis and treatment are vital in the control of hepatitis, with prison providing an opportunity to do so and therefore reduce downstream costs to both the patient and the NHS from the complications of hepatitis. ${ }^{4}$

Several improvements in the quality of BBV service provision at HMP Birmingham have been observed between the reviews in 2013 and 2015. The majority of actions from the initial review have been implemented, or are in progress. Three were disregarded as unnecessary or unfeasible, and the remaining one yet to be implemented has been placed on the revised action plan stemming from the current review (online supplementary appendix 2).

Many national standards for BBV services are currently being met by the establishment, but some only partially. This is addressed in the revised action plan.

Quantitative improvement over the 2-year period, although modest, has been observed in testing coverage although vaccination coverage has dipped slightly. As alluded to, this is largely due to prisoners who refuse vaccination, suggesting that steps need to be taken to encourage their understanding and make this more amenable to them.

\section{Recommendations and action plan}

The recommendations resulting from this review were divided between actions for the project author, prison 
healthcare staff and NHS England. These focused on specific details discussed in the Strategies for improvement section, broadly covering methods to enhance both prison staff and prisoner education, standardise the information provided to prisoners, encourage $\mathrm{BBV}$ vaccination and testing uptake, improve communication between prison staff and PHE, make service delivery easier and more efficient, and ongoing service review. Full details are included in online supplementary appendix 2.

\section{Progress update}

The project author met with the lead BBV nurse in December 2016 for a brief update on progress since the actions were recommended.

All of the actions recommended for the project author have been produced or implemented thus far.

The BBV nurses have successfully produced a guidance document for other healthcare staff regarding BBV which can be used for health promotion at every contact. Actions regarding changing the style of offer of vaccination or testing, and offering these together, have been implemented, and the test results letter has been modified to include a reminder for vaccination. It is now also ensured that the induction checklist includes the offer of vaccination to every single patient, as well as of BBV testing. A spreadsheet for hepatitis B data as well as hepatitis $\mathrm{C}$ is now kept, as recommended.

Prisoner forum meetings are now including BBV as a topic for discussion. One of the most successful implementations of the action plan has been the training of other healthcare staff in DBST which has been carried out among the majority of staff in the drug and alcohol team and mental health teams. However, now that DBST is fully implemented, early issues are beginning to transpire with the efficiency of its use. Prisoners are favouring this technique, but it is not as efficient as it seems due to lengthy paperwork required by the laboratory for sample processing. This is something that may need to be addressed by subsequent reviews.

The remaining recommendations are still pending.

A comprehensive further review is recommended.

Acknowledgements TA would like to thank Mamoona Tahir and Jackie Roberts of Public Health England for their advice and support during the undertaking of this project and also Derek Tobin, Natasha Drummond and Yvette Carroll at HMP Birmingham for their cooperation with the project and insight into the healthcare services at the prison.

Contributors TA led this project, performed the necessary background research, collected data, collated and analysed results, devised and implemented a new action plan, wrote up and submitted this manuscript.

Funding The authors have not declared a specific grant for this research from any funding agency in the public, commercial or not-for-profit sectors.

Competing interests None declared.

Patient consent Not required.
Ethics approval This study is not classed as research by the NHS Health Research Authority, hence formal ethical approval was not required, as the focus is on service improvement in general rather than individual patients.

Provenance and peer review Not commissioned; externally peer reviewed.

Open access This is an open access article distributed in accordance with the Creative Commons Attribution Non Commercial (CC BY-NC 4.0) license, which permits others to distribute, remix, adapt, build upon this work non-commercially, and license their derivative works on different terms, provided the original work is properly cited, appropriate credit is given, any changes made indicated, and the use is non-commercial. See: http://creativecommons.org/licenses/by-nc/4.0/.

\section{REFERENCES}

1. G4S. Welcome to HMP Birmingham. http://hmpbirmingham.co.uk/ index.php (Accessed 27 Jul 2016).

2. G4S. Welcome to HMP Birmingham- Healthcare. http:// hmpbirmingham.co.uk/about/about-haw/about-haw-h/ (Accessed 27 Jul 2016).

3. Prison Reform Trust. Prison: The Facts- Bromley Briefings Summer. 2015. [online] http://www.thebromleytrust.org.uk/files/ prisonfactsmay2015.pdf (Accessed 27 Jul 2016).

4. Hug B. Hepatitis C Trust. Addressing hepatitis $C$ in prisons and other places of detention: Recommendations to NHS England by a prison health expert group convened by The Hepatitis C Trust. 2013. [online] http://www.hcvaction.org.uk/sites/default/files/resources/HCV\% 20in\%20Prisons.pdf (Accessed 20 Jun 2017).

5. Edgar K, Azad Y, Valette D. HIV and Hepatitis in UK Prison: Addressing Prisoners' Healthcare Needs: Prison Reform Trust, National Aids Trust, 2005.

6. Yamey G. Prisoners in england and wales are at risk of bloodborne viruses. BMJ 2000;320:1493.

7. Kronfli N, Linthwaite B, Kouyoumdjian F, et al. Interventions to increase testing, linkage to care and treatment of hepatitis $C$ virus (HCV) infection among people in prisons: A systematic review. Int $\mathrm{J}$ Drug Policy 2018;57:95-103.

8. Tavoschi L, Vroling H, Madeddu G, et al. Active Case Finding for Communicable Diseases in Prison Settings: Increasing Testing Coverage and Uptake Among the Prison Population in the European Union/European Economic Area. Epidemiol Rev 2018;40:105-20.

9. Teagle R, Rehman Y, Edeghere O. Hepatitis $C$ in the West Midlands: 2013 Data: Public Health England, 2015.

10. Teagle R, Rehman Y, Edeghere O. Hepatitis B in the West Midlands: 2013 Data: Public Health England, 2015.

11. MacAlister E. Review and sharing of best practice in relation to Hep $B$ and Hep $C$ services in West Midlands Prisons: Public Health England, 2013.

12. National Aids Trust. Tackling blood-borne viruses in prisons: a framework for best practice in the UK: NAT, 2011.

13. The National Institute for Health and Care Excellence. Hepatitis $B$ and $C$ testing: people at risk of infection. PH43. London: NICE, 2012.

14. Ramsay M, Noakes $\mathrm{K}$, Salisbury D, eds. Immunisation against infectious disease. 3rd ed. London: The Stationary Office, 2006.

15. National Offender Management Service, Public Health England, NHS England. National Partnership Agreement between: The National Offender Management Service, NHS England and Public Health England for the Co- Commissioning and Delivery of Healthcare Services in Prisons in England. 2015-2016. [online]. https://www. gov.uk/government/uploads/system/uploads/attachment_data/file/ 460445/national_partnership_agreement_commissioning-deliveryhealthcare-prisons_2015.pdf (Accessed 20 Jun 2017).

16. Public Health England. Opt-out BBVs (Hepatitis B, C and HIV) Testing Algorithm. London: PHE, 2015. PHE 2014041.

17. Public Health England. Blood-borne Virus Opt-Out Testing in Prisons: Preliminary evaluation of pathfinder programme. $2014 \mathrm{https} / / / \mathrm{www}$. gov.uk/government/uploads/system/uploads/attachment_data/file/ 428942/BBV_pathfinder_evaluation_Phase_1_FINAL.PDF (Accessed 13 Dec 2015).

18. Public Health England. Guidance- Notifiable diseases and causative organisms: how to report. London: Public Health England, 2010.

19. Birmingham City Council. 2011 Census: Birmingham Population and Migration Topic Report: Planning \& Growth Strategy, Birmingham Council, 2013. 